 P-ISSN:1907-4328, E-ISSN : 2685-4376/P. 19-36
}

\section{Perlawanan Ahli Hadis Terhadap Gerakan Radikalisme dalam Konstruksi Media Online}

\author{
Kun Wazis \\ Institut Agama Islam Negeri Jember \\ kunwazis@gmail.com
}

\begin{abstract}
Resistance to radicalism which is allegedly endemic on campuses has been carried out by many elements. One of which was carried out by Imam Syafi'i Islamic Academy (STDI) Jember and the Indonesian Hadith Science Association (ASILHA) by holding an International Seminar on the Role of Classical and Contemporary Hadith Experts in Combating Radicalism which news and opinions were massively constructed by various online media. This study attempted to answer the questions about the construction of online media reality in narrating the resistance of STDI Imam Syafii Jember towards the dangers of radicalism in Indonesia and the world. Through descriptive qualitative study with Halliday's model discourse analysis, this study was conducted by critical observation of online media news text of Sindonews.com. As a result, STDI Imam Syafii ember recommended that radicalism is a form of extreme and exaggeration in religious matters that must be resisted. Meanwhile, adhering to the teachings of Islam, choosing a straight-moderate method, and carrying out the Shari'a of Allah comprehensively, are not categorized as a form of radicalism.
\end{abstract}

Keywords: Hadith Experts’ Resistance, Radical Movement, Online Media

\section{Abstrak}

Perlawanan terhadap radikalisme yang disinyalir mewabah di kampus-kampus telah dilakukan oleh banyak elemen. Salah satunya dilakukan oleh Akademi Islam Imam Syafi'i (STDI) Jember dan Asosiasi Ilmu Hadis Indonesia (ASILHA) dengan menggelar Seminar Internasional Peran Pakar Hadis Klasik dan Kontemporer dalam Memerangi Radikalisme yang berita dan Opini dikonstruksi secara masif oleh berbagai media online. Penelitian ini berusaha menjawab pertanyaan tentang konstruksi realitas media online dalam menceritakan perlawanan STDI Imam Syafii Jember terhadap bahaya radikalisme di Indonesia dan dunia. Melalui studi kualitatif deskriptif dengan analisis wacana model Halliday, penelitian ini dilakukan dengan observasi kritis terhadap teks berita media online Sindonews.com. Alhasil, STDI Imam Syafii bara menyarankan agar radikalisme merupakan bentuk ekstrem dan berlebihan dalam urusan agama yang harus dilawan. Sementara itu, menganut ajaran Islam, memilih metode lurus-moderat, dan menjalankan syariat Allah secara komprehensif, tidak dikategorikan sebagai bentuk radikalisme.

Kata Kunci: Perlawanan Ahli Hadis, Gerakan Radikal, Media Online 


\section{Pendahuluan}

Fenomena kampus STDI Imam Syafii Jember ${ }^{1}$ menggelar seminar internasional bertajuk perlawanan terhadap radikalisme menarik untuk diteliti dengan berbagai pertimbangan. Pertama, kehadiran lembaga pendidikan Islam ini sempat menimbulkan ketegangan di masyarakat Jember karena perbedaan cara pandang dalam pemahaman keagamaan Islam. Puncak ketegangan itu, berupa demonstrasi aksi massa warga Nahdlatul Ulama (Nahdliyin) yang tergabung dalam Aksi Topi Bangsa (Tolak Penjajahan Ideologi Bangsa) dengan menuntut penutupan STDI Imam Syafii karena dituduh menghina kyai ${ }^{2}$.

Ketegangan tersebut berakhir damai setelah dilakukan media antara pihak Kementarian Agama Kabupaten Jember, PCNU Kabupaten Jember, MUI Jember, STDI Imam Syafii Jember, dan perwakilan Aksi Topi Bangsa. Dalam pertemuan yang digelar dalam rangka Konsolidasi dan Koordinasi Antar Tokoh Agama SeKabupaten Jember di Kantor Kementerian Agama Kabupaten Jember pada Rabu, 15 Agustus 2018 itu, disepakati antara STDI Imam Syafii dan Warga Masyarakat Nahdliyin Kabupaten Jember dengan 6 poin kesepakatan. Diantaranya butir ke-2 dan ke-3 kesepakatan itu adalah, "saling menghargai dengan sikap bekerjasama pada hal-hal yang disepakati dan toleransi pada hal-hal yang berbeda. Tidak menyebarkan paham yang diyakini kepada pihak lain yang memiliki paham yang berbeda dalam bentuk apapun." ${ }^{3}$ Kesepakatan masih memiliki potensi konflik lanjutan jika tidak ada keinginan kedua belah pihak untuk menahan diri dan konsisten dengan kesepakatan tersebut. Dan, hingga satu tahun kesepakatan dibuat, berdasar-

\footnotetext{
${ }^{1}$ Berdirinya STDI Imam Syafii Jember berawal dari satu obrolan ringan beberapa mahasiswa Indonesia yang sedang menempuh studi di Islamic University Of Madinah Saudi Arabia sekitar tahun 2005. Pada tahun 2007 berdirilah ma'had 'aly Imam Syafii, sebagai cikal bakal STDI Imam Syafii. Dan sejak saat itu pula, tahapan tahapan perizinan pendirian Sekolah Tinggi dimulai, selangkah demi selangkah. Hingga pada akhirnya, pada tahun 2010, Departemen Agama, melalui Dirjen Pendidikan Tinggi Agama Islam, menerbitkan izin operasional bernomorkan Dj.I/375/2010. Dan sejak saat itu pula, secara resmi ma'had 'ali Imam Syafii , berganti nama menjadi Sekolah Tinggi Dirasat Islamiyah Imam Syafii atau disingkat menjadi STDI Imam Syafii.Periksa profil lengkap STDI Imam Syafii pada laman http://stdiis.ac.id/profil/sejarahsingkat/

2 Pada tanggal 3 Agustus 2018 aksi massa Topi Bangsa meminta Pemkab Jember dan DPRD Jember agar menutup institusi STDI Imam Syafii karena dinilai meresahkan dan mengganggu ketentraman masyarakat. Desakan Topi Bangsa ini ditolak oleh pihak STDI Imam Syafii dengan membuktikan hubungan yang terjalin baik dengan masyarakat sekitar kampus. https://faktualnews.co/2018/08/03/anggap-stdi-diskriditkan-kiai-ratusan-massa-topi-bangsawadul-ke-dewan/92122/

${ }^{3}$ Pertemuan antara pihak STDI Imam Syafii dengan massa Topi Bangsa difasilitasi oleh Kapolres Jember. Hadir dalam pertemuan tersebut, diantaranya pihak Kemenag Kabupatan Jember, MUI Jember, PCNU Jember, FKUB Jember, GP Anbshor, LDNU, dan sejumlah tokoh NU dan Muhammadiyah di Jember. http://www.moslemtoday.com/ketegangan-antara-warga-nahdliyyindan-stdi-imam-syafii-jember-akhirnya-mencair/
} 
kan pengamatan peneliti, tidak terjadi konflik baru.

Kedua, STDI Imam Syafii sebagai lembaga pendidikan yang memadukan kurikulum Universitas Islam Madinah dengan STDI dinilai menyebarkan ajaran Wahabi yang mempersoalkan ajaran-ajaran warga Nahdliyin di Jember yang dianggap sudah lazim, seperti Maulid Nabi. Paham Wahabi dinilai memicu ketegangan masyarakat karena dinilai tidak sejalan dengan pandangan keagamaan NU yang berpegang pada ajaran Ahlussunnah wal Jamaah. Perbedaan paham inilah yang menjadi poin penting kesepakatan agar tidak menyebarkan paham yang diyakini kepada pihak lain yang memiliki paham berbeda dalam bentuk apapun sebagai butir kesepakatan poin ketiga ${ }^{4}$.

Ketiga, seminar internasional yang digelar oleh STDI Imam Syafii dan ASILHA $^{5}$ pada tanggal 20-22 September 2019 dengan mengusung isu perlawanan terhadap radikalisme oleh para Ilmuwan Ahli Hadis dari berbagai negara di Timur Tengah menunjukkan adanya perspektif yang sama dengan komunitas muslim mayoritas di Indonesia bahwa radikalisme merupakan musuh umat Islam. Pembicara-pembicara utama dari 6 negara yang dihadirkan adalah Prof. Dr. Abdullah bin Abdul Aziz Al Faaleh, M.A. (Guru Besar hadis dan Dekan Fakultas Hadis, Universitas Islam Madinah, Arab Saudi), Prof. Dr. Ali Ibrohim Saud Ajiin, M.A. (Guru Besar hadis dan Ketua Asosiasi Ilmu Hadis Yordania), Prof. Dr. Fathur Rahman Qurasyi, M.A. (Guru Besar hadis dan Ketua Program Studi Hadis, Universitas Islam International Islam Abad, Pakistan), Prof. Dr. Abdus Sami' Muhammad Anis, M.A. (Guru Besar hadist, Fakultas Syari'ah, Universitas Sharjah, Uni Emirat Arab), Prof. Dr. Mahmud Abdullah Abdul halim, M.A. (Guru Besar hadis, Fakultas Ushuludin, Universitas Al Azhar, Mesir), Prof. Dr. Muhammad Abdur Razaq, M.A. (Guru Besar hadis, Universitas Abdur Rahman bin Faishol, Dammam, Arab Saudi), Dr. H. M. Al Fatih, M.A. (Ketua Asosiasi Ilmu Hadis Indonesia) dan Dr. Ali Musri Semjan Putra, M.A. (Perintis dan Pendiri STDI Imam Syafi'i Jember) ${ }^{6}$.

\footnotetext{
${ }^{4}$ Menurut Kapolres Jember AKBP Kusworo Wibowo, ketegangan yang berakhir dengan kesepakatan itu dapat menjaga kondusifitas wilayah Jember. Dengan terbitnya kesepakatan ini, menurut Kapolres Jember saat itu, Kusworo, komunikasi antara dua belah pihak yang semula berseteru semakin mudah. Periksa pada laman http://m.beritajatim.com/politik pemerintahan/336542/kontroversi_wahabi_di_jember_berakhir_damai.html

${ }^{5}$ Dalam laman resmi asilha.com disebutkan bahwa sebagai sebuah ijthad dalam rangka mengembangkan kajian Studi Hadis di Indonesia dibentuklah sebuah perkumpulan yang dinamakan dengan Asosiasi Ilmu Hadis Indonesia (ASILHA). Sebagai sebuah perkumpulan ASILHA menghimpun beragam pemerhati hadis di Indonesia. Himpunan ini terdiri atas akademisi dan praktisi hadis di Indonesia dengan memiliki tujuan yang sama. Profil ASILHA selengkapnya dapat diakses melalui https://www.asilha.com/tentang/

${ }^{6}$ Selain media massa online yang memuat hasil seminar internasional, STDI Imam Syafii juga menarasikan melalui website media online resmi kampusnya dalam laman http://stdiis.ac.id/ berita/hadirkan-ahli-hadis-dari-6-negara-dalam-seminar-internasional-stdiis-jember-pangkasdefinisi-liar-masyarakat-tentang-radikalisme/
} 
Keempat, perlawanan terhadap radikalisme sebagai isu besar di dunia yang diseminarkan oleh STDI dan ASILHAkemudian dikomunikasikan melalui media massa. Diantara media online yang ikut memberitakan adalah mediaindonesia.com ${ }^{7}$ (media siber dibawah Media Grup milik Surya Paloh), republika.or.id ${ }^{8}$ (media online di bawah Mahaka Grup milik Erick Thohir), dan media sindonews.com ${ }^{9}$ (media internet di bawah MNC Grup milik Hari Tanoesoedibjo). Sebagai bentuk perlawanan itu, media massa dijalin oleh pihak STDI dan ASILHA sebagai panitia untukmemberitakan dan mengopinikan penolakan mereka terhadap paham radikal yang berkembang di dunia, termasuk di Indonesia.

Berdasarkan keempat argumentasi tersebut, penulis tertarik untuk meneliti hasil konstruksi teks berita yang ditampilkan oleh media siber mengenai wacana perlawanan terhadap radikalisme dalam seminar internasional yang digelar STDI Imam Syafii dan ASILHA ini. Pilihan terhadap website Sindonews.com dilatarbelakangi oleh kelengkapan berita yang ditampilkan oleh Sindonews, yakni sebelum seminar internasional yang diberitakan Edisi Rabu 18 September $2019^{10}$ dan berita hasil dari rekomendasi seminar yang dikonstruksikan Sindownews pada Minggu 22 September $2019^{11}$. Sedangkan media online lainnya, seperti Republika Online, Merdeka.com ${ }^{12}$, dan Media Indonesia.com hanya memuat dari satu sisi pada sebelum dan saat acara berlangsung. Ketiganya tidak memuat hasil rekomendasi yang dicetuskan dalam seminar yang berlangsung di Hotel Dafam Jember.

\section{Metode Kajian}

Kajian dalam artikel ini merupakan penelitiandeskriptif kritis dengan menggunakan analisis wacana model Halliday yang memfokuskan pada dua dimensi penting. Pertama, penulis menganalisis secara deskriptif kritis makna radikalisme sebagai isu yang selalu diperebutkan oleh banyak kalangan dengan berbagai kepentingan.Untuk mendapatkan data mengenai tarik-menarik wacana

\footnotetext{
${ }^{7}$ Beritanya dapat diakses melalui https://mediaindonesia.com/read/detail/260994-stdi-imamsyafii-gelar-seminar-internasional-cegah-radikalisme

${ }^{8}$ Berita tentang seminar bisa diakses melalui web media siber Republika online pada laman https://khazanah.republika.co.id/berita/py212e313/ulama-hadis-dunia-gelar-seminar-di-jemberbahas-radikalisme

${ }^{9}$ Berita tentang seminar dapat diakses melalui laman resmi Sindownews pada kolom Jatim di https://jatim.sindonews.com/read/14618/1/stdi-imam-syafii-jember-buat-seminar-internasionalkupas-peran-ulama-ahli-hadits-tanggulangi-radikalisme-1568786983

10 Berita selengkapnya dapat diakses melalui laman resmi media online sindonews pada websitehttps://jatim.sindonews.com/read/14618/1/stdi-imam-syafii-jember-buat-seminarinternasional-kupas-peran-ulama-ahli-hadits-tanggulangi-radikalisme-1568786983

${ }^{11}$ Periksa beritanya pada laman https://jatim.sindonews.com/read/14802/1/ini-rekomendasiseminar-internasional-peranan-ahli-hadits-klasikkontemporer-menanggulangi-radikalisme1569290997

${ }^{12}$ Periksa beritanya di laman https://www.merdeka.com/peristiwa/menolak-stigma-jenggot-dancelana-cingkrang-identik-dengan-radikalisme.html
} 
radikalisme itu, penulis menggunakan studi literatur dengan menggali sumber buku yang relevan, termasuk berita-berita media massa dan media sosial. Seminar internasional yang digelar STDI Imam Syafii Jember dan ASILHA Indonesia pada 20-22 September 2019 ini juga tidak bisa dilepaskan dari kepentingan pihak STDI Imam Syafii Jember dengan ASILHA dalam melawan stigma negatif radikalisme yang dikait-kaitkan dengan ajaran Islam identitas seorang muslim, seperti berjenggot, bercelana cingkrang, dan perempuan bercadar ${ }^{13}$.

Kedua, penulis menggunakan analisis wacana Model Halliday untuk mengungkapkan wacana radikalisme yang dilawan oleh STDI Imam Syafii Jember dan ASILHA dengan melihat perspektif media online Sindonews.com sebagai pihak luar yang mengkonstruksikan peristiwa seminar internasional bertema peran ahli hadis dalam penanggulangan radikalisme. Model Wacana Halliday ini dinilai tepat oleh peneliti karena ada tiga dimensi penting yang digali, yakni medan wacana (field of discourse), pelibat wacana (tenor of discourse), dan mode wacana (mode of discourse ${ }^{14}$.

Dalam medan wacana, penulis meneliti dua berita Sindonews.com untuk menggambarkan realitas tindakan sosial yang terjadi dalam peristiwa yang diwacanakan secara online kepada audience media tersebut. Substansi peristiwa penanggulangan radikalisme yang dilakukan oleh para ahli hadis dan sumber yang dipilih dalam menggambarkan seminar internasional yang digelar STDI Imam Syafii Jember dan ASILHA merupakan tindakan sosial sumber berita sekaligus mewakili sebagian cara pandang (perspektif) secara sosial media online Sindonews.com

Dalam pelibat wacana, penulis meneliti identitas sumber-sumber berita yang ditampilkan oleh media Sindonews.com dalam mengonstruksi seminar internasional yang digelar STDI Imam Syafii Jember dan ASILHA melalui sumber berita yang dipilih. Kebijakan redaksi Sindownews.com memilih narasumber untuk mengonstruksi berita yang di-upload secara online kepada khalayak luas (pengakses online) menjadi penting untuk diketahui kedudukan dan peranan mereka dalam memaknai realitas.

Dalam konteks mode wacana, penulis meneliti secara kritis pilihan bahasa yang ditampilkan Sindonews.com dalam dua edisi yang mengonstruksikan berita seminar internasional bertajuk peran ahli hadis klasik dan kontemporer dalam menanggulangi radikalisme di Indonesia dan dunia. Dalam hal ini, penulis menjelaskan gaya bahasa dan pengaruhnya yang digunakan Sindonews.com, baik yang bersifat eksplanatif, deskriptif, persuasif, hiperbolis, dan sejenisnya. Gaya ba-

\footnotetext{
${ }^{13}$ Periksa beritanya pada website https://mediaindonesia.com/read/detail/260994-stdi-imamsyafii-gelar-seminar-internasional-cegah-radikalisme.

${ }_{14}$ Periksa Rachmat Kriyantono, Teknik Praktis Riset Komunikasi (Jakarta: Kencana Prenada Media Group, 2012), 263.
} 
hasa yang dipilih dapat memperkuat wacana yang dikembangkan oleh media melalui berita yang ditampilkan dalam halaman Online.

Pemilihan wacana ini sebagai alat analisis mendasarkan pada pandangan Ricoeur yang dikutip Haryatmoko ${ }^{15}$ bahwa wacana memiliki empat unsur, yaitu pertama, ada subyek yang menyatakan; kedua, kepada siapa disampaikan; ketiga dunia atau wahana yang mau direpresentasikan; dan keempat, temporalitas atau konteks waktu. Aplikasi dari wacana Ricouer ini adalah, pertama, sumber berita yang dipilih dan ditampilkan oleh Sindonews.com dapat mewakili pandangan STDI Imam Syafii Jember dan ASILHA dalam realitas berita. Kedua, realitas berita online Sindonews.com memiliki siapa saja khalayak yang mengakses berita sehingga menjadi sasaran realitas yang dituju/ dipengaruhi. Ketiga, konstruksi realitas berita yang disebarluaskan oleh media online Sindonews.com merepresentasikan wahana tertentu atas pesan yang disampaikan STDI dan ASILHA. Keempat, karena menyangkut even seminar internasional yang terbatas oleh waktu, maka berita yang dipilih sesuai dengan konteks peristiwa yang diwacanakan dalam berita.

Dalam penelitian ini, nilai penting yang dapat dipetik secara axiologis mengacu pandangan Mulyana ${ }^{16}$ bahwa wacana media massa pada dasarnya menawarkan kerangka makna alternatif kepada khalayak untuk mendefinisikan diri sendiri, orang lain, lingkungan sosial, peristiwa-peristiwa dan objek-objek di sekitar kita. Fenomena kampus STDI Imam Syafii yang oleh sebagian masyarakat dipersepsikan mewakili pandangan Wahabi, Salafi, dan 'radikal', dalam konteks pemberitaan Sindonews.com yang diteliti menyajikan konstruksi lain dalam hal perlawanan kampus ini terhadap bahaya radikalisme.

\section{Pertarungan Wacana Radikalisme}

Istilah dan wacana radikal dan radikalisme sudah lama menjadi perhatian serius kalangan pemikir Islam di Indonesia. Sejak dari istilah bahasa, antara radikal dan radikalisme menimbulkan perdebatan hingga saat ini karena makna komunikasi dapat berkembang dan tidak bersifat tunggal, serta multiperspektif. Apabila ditelusuri secara ontologis, kata radikal memiliki makna yang netral, tidak berpihak, bebas nilai. Dalam sejumlah referensi kata radical atau radix memiliki arti "sama sekali" atau sampai ke akar akarnya. Apabila ditarik dalam konteks sebuah tanaman, sebuah pohon yang tidak memiliki akar, maka dia tidak akan dapat subur, dan dalam waktu tertentu pohon akan mengalami kematian atau musnah.

\footnotetext{
${ }^{15}$ Haryatmoko, Critical Discourse Analysis (Analisis Wacana Kritis): Landasan Teori, Metodologi dan Penerapan (Jakarta: Rajawali Pers, 2016), 5. Menurut Haryatmoko, pemahaman unsure-unsur wacana Ricoeur ini bias membantu menjelaskan mengapa oleh Foucault dan Wetherell, wacana dilihat sebagai praksis sosial karena wacana sudah merupakan tindakan. Wacana bisa dianalisis dalam kerangka aktivitas relasi sosial dan teknologi komunikasi.

${ }^{16}$ Deddy Mulyana, Komunikasi Massa: Kontroversi, Teori dan Aplikasi (Bandung: Widya Padjadjaran, 2008), 12.
} 
Menurut Syuderajat" ${ }^{17}$ makna kata "radikalisme" cenderung lebih netral karena dapat menjadi label bagi aksi-aksi yang tidak hanya berlandaskan religi tertentu namun juga terjadi pada wilayah aksi ideologi politik ekonomi. Bahkan berlandaskan pada makna etimologi, kata "radikalisme" berasal dari bahasa latin yaitu: radic yang memiliki arti "akar". Sehingga makna kata "radical" dapat juga dimaknakan "mengakar" atau "mendasar". Dengan demikian "radikalisme" adalah aliran (isme/ideologi) yang mengakar atau mendasar serta pengejawantahannya juga mengakar atau mendasar. Kurang lebih, kata "radikalisme" dapat disepadankan dengan kata "fundamentalisme".

Suatu Ilmu yang tidak tak dipahami sampai akar-akarnya, maka seseorang tidak akan pernah mendapatkan pemahaman yang mendalam dan menyeluruh. Oleh karena dalam pandangan filsafat komunikasi, disebutkan tentang ciri-ciri berfikir filsafat adalah radikal, yang bermakna menyeluruh, sampai ke akar-akarnya. Jika ditarik dalam Kamus Besar Bahasa Indonesia (KBBI), secara terminologi kata radikal berarti (1) secara mendasar (sampai kepada hal yang prinsip); (2) amat keras menuntut perubahan (undang-undang, pemerintahan); (3) maju dalam berfikir atau bertindak $^{18}$. Dengan demikian secara epistemologi, kata radikal mulai diarahkan kepada interpretasi kepada sebuah pikiran atau tindakan untuk sebuah perubahan. Bertindak radikal memiliki makna komunikasi positif karena menghendaki perubahan secara mendasar.

Berbeda kalau kemudian kata radikal ini dikonstruksi dalam kontek faham (isme). Sebagai disebutkan dalam KBBI diartikan secara terminologis adalah (1) Paham atau aliran yang radikal dalam politik; (2) paham atau aliran yang menginginkan perubahan atau pembaharuan sosial dan politik dengan cara kekerasan atau drastis; dan (3) sikap ekstrem dalam aliran politik ${ }^{19}$. Berdasarkan pemaknaan radikalisme ini, maka paham radikalisme dapat disematkan secara umum kepada setiap individu, kelompok, dan negara yang memiliki ketiga ciri tersebut. Maknanya berbeda dengan radikal yang masih bersifat netral, tetapi radikalisme mengarah kepada sesuatu paham yang negatif karena dilekatkan dengan cara-cara kekerasan. Demikian juga ketika didampingkan dengan radikalisme agama, maka konotasinya menjadi negatif, buruk, dan harus dilawan.

Pemaknaan ini sebagaimana ditulis Mochtar Buchori berjudul "Radikalisme

\footnotetext{
17 Fajar Syuderajat, Ideologi Surat Kabar dalam Pemberitaan Terorisme (Bandung: Jurnal Dakwah dan Komunikasi UIN Sunan Gunung Djati Vo. 1, No. 1, 2017), 10-11. Memang kalau ditelusuri dari akar kata radical bisa disamaartikan (synonym) dengan kata "fundamentalis" dan "extreme". 'Radikalisme' berasal dari bahasa Latin "radix, radicis", artinya akar ; (radicula, radiculae: akar kecil). Berbagai makna radikalisme, kemudian mengacu pada kata "akar" atau mengakar.

${ }^{18}$ Periksa KBBI dalam kamus online pada laman https://kbbi.web.id/radikal, diakses 22 Oktober 2019.

${ }^{19}$ Periksa pada laman resmi KKBI di https://kbbi.web.id/radikalisme, diakses 22 Oktober 2019.
} 
Agama" yang dimuat Majalah Pesantren Tahun $1986^{20}$ mengungkapkan empat julukan yang popular saat itu, yakni radikal, fundamentalis, ekstrim, dan militan. Menurut Buchori, lazimnya keempat julukan atau ajektif ini dipergunakan dengan nada menghukum atau merendahkan, dengan nada pejoratif. Jadi bila suatu gerakan keagamaan mendapatkan cap "radikal", "fundamentalis", "ekstrim", atau "militan", maka masyarakat pada umumnya akan segera menjauhinya atau mengucilkannya. Hal yang sebaliknya pun sering pula terjadi.

Badan Nasional Penanggulangan Terorisme (BNPT) sendiri memaknai radikalisme yang disebutnya sebagai embrio paham yang melahirkan terorisme. Menurut BNPT, radikalisme merupakan suatu sikap yang mendambakan perubahan secara total dan bersifat revolusioner dengan menjungkirbalikkan nilai-nilai yang ada secara drastis lewat kekeraan (violence) dan aksi-aksi yang ekstrem. Ada beberapa ciri yang bisa dikenali dari sikap dan paham radikal. 1) intoleran (tidak mau menghargai pendapat \&keyakinan orang lain), 2) fanatik (selalu merasa benar sendiri; menganggap orang lain salah), 3) eksklusif (membedakan diri dari umat Islam umumnya) dan 4) revolusioner (cenderung menggunakan cara-cara kekerasan untuk mencapai tujuan $)^{21}$.

Berdasarkan definisi tersebut, radikal dan radikalisme sebenarnya memiliki makna komunikasi yang berbeda ketika dikonteksnya dengan paham keagamaan. Islam sebagai agama rahmatan lil alamin merupakan agama yang radikal, karena dalam mempelajari Islam pemeluknya diajak untuk memahami secara menyeluruh dan menjalankan agamanya dengan totalitas (Islam Kaffah). Sedangkan radikalisme bertentangan dengan Islam karena dalam menerapkan atau menjalankan agama dengan menyeluruh itu, Islam tidak mengajarkan kekerasan. Hal ini dibuktikan dengan praktik dakwah Nabi Muhammad SAW yang menyebarluaskan Islam tidak dengan cara kekerasan. Dalam konteks inilah, radikalisme dilawan oleh komunitas muslim yang menyandarkan kepada tuntutan dakwah ramah Rasulullah SAW.

Dalam konteks ini, konstruksi media massa internet Sindonews.com memberitakan seminar internasional tentang perlawanan terhadap radikalisme yang dilakukan para ahli hadis klasik-kontemporer di era masyarakat digital saat ini menemukan kemenarikannya. Sebagaimana dinyatakan Ghifari, pertama, bahwa

\footnotetext{
${ }^{20}$ Mochtar Buchori, Radikalisme Agama: Sebuah Catatan Awal (Jakarta: Majalah Pesantren No. 4/ Vol. III/ 1986), 57. Majalah Pesantren diterbitkan sebagai media informasi dan komunikasi serta wadah pengajian untuk membangkitkan kepedulian dan wawasan pengembangan melalui jalur pemikiran yang bertolak pada titik pandang keagamaan. Majalah Pesantren diterbitkan oleh Perhimpunan Pengembangan Pesantren dan Masyarakat (P3M). P3M sendiri berdiri pada 18 Mei 1983 di Jakarta oleh sejumlah pengasuh pondok pesantren. Dewan redaksinya diantaranya Abdurrahman Wahid, Abdullah Syarwani, Adi Sasono, M. Dawam Rahardjo, Djohan Effendy, Said Budairy, Soetjipto Wirosardjono,m Zamakhsyari Dhofier, dan Musfihin Dahlan.

${ }_{21}$ https://belmawa.ristekdikti.go.id/wp-content/uploads/2016/12/Strategi-Menghadapi-PahamRadikalisme-Terorisme.pdf
} 
media internet mengambil porsi dan peranan yang sangat besar dalam memberikan informasi kepada publik, terutama kaum muda akan ideologi radikal. Kedua, media massa memegang peran kunci dalam menangkal dan memberikan informasi ke publik terhadap isu-isu radikalisme sehingga masyarakat dapat melakukan tindakan pencegahan berkembangnya gerakan-gerakan ekstrimis dimulai dari lingkungannya sendiri $^{22}$.

\section{Medan Wacana Perlawanan atas Radikalisme}

Berdasarkan berita pertama yang diteliti, medan wacana yang ditampilkan dalam berita Sindonews pada Edisi Rabu 18 September 2019 adalah peristiwa/ kejadian Seminar Internasional yang digelar STDI Imam Syafii dengan tema peran ulama ahli hadis menanggulanggi radikalisme. Dalam berita yang diunggah pukul 10.05 WIB itu, yakni dua hari sebelum seminar digelar, Sindonews.com mengawali lead (kepala berita) tentang penyelenggaraan Seminar Internasional yang bertema Peranan Ahli Hadis Klasik dan Kontemporer dalam Menanggulangi Radikalisme.

Digambarkan oleh Sindonews.com bahwa seminar yang diselenggarakan sebagai upaya untuk mengenal realitas radikalisme, penyebab radikalisme, bentukbentuk radikalisme, dan solusi menanggulangi radikalisme. Untuk memperkuat tujuan seminar yang dilaksanakan pada 20-22 September 2019 itu, Sindonews.com mengutip siaran pers dari ketua panitia seminar, yakni Dr. Ali Musri Semjan Putra, MA. Kalimat yang dipilih adalah sebagai berikut:

"Dewasa ini isu radikalisme semakin marak, akan tetapi terjadi penafsiranpanafsiran yang liar tentang radikalisme yang dijadikan sebagai alat untuk memfitnah dan memprovokasi dalam perbedaan......Akhirnya masyarakat membiasakan berbagai upayayang dilakukan untuk menanggulangi radikalisme itu sendiri,"

Dalam berita ${ }^{23}$ yang ditulis oleh reporter Sindonews.com, Vitrianda Hilba Siregar(vhs) diperkuat dengan foto kampus STDI Imam Syafii Jember, bukan Hotel Dafam Jember sebagai venue/ tempat seminar berkelas internasional itu berlangsung. Penonjolan konstruksi foto sebagai penguat peristiwa ini menunjukkan bahwa

\footnotetext{
22 Iman Fauzi Ghifari, Radikalisme di Internet (Bandung: Religious, Jurnal Agama dan Lintas Budaya UIN Sunan Gunung Djati, Vol. 1, No.2, Maret 2017), 127.

${ }^{23}$ Berita, dalam konteks komunikasi massa yang berkembang sampai sekarang, selalu muncul dalam benak dan pikiran manusia. Berita yang disusun dalam benak manusia bukan merupakan peristiwa manusia. Berita bukan adalah peristiwa itu sendiri. Berita merupakan usaha rekonstruksi kerangka peristiwa yang terjadi. Maka, berita dalam konteks komunikasi massa, lebih merupakan inti yang disesuaikan dengan kerangka acuan yang dipertimbangkan agar peristiwa itu memiliki makna bagi para pembacanya. Periksa Fajar Syuderajat, Ideologi Surat Kabar dalam Pemberitaan Terorisme (Bandung: Jurnal Dakwah dan Komunikasi UIN Sunan Gunung Djati Vo. 1, No. 1, 2017), 4.
} 
STDI Imam Syafii merepresentasikan kampus yang memiliki otoritas menggambarkan realitas seminar. Foto diperkuat dengan dukungan teks, "Sekolah Tinggi Dirasat Islamiyah (STDI) Imam Syafii akan mengadakan Seminar Internasional. (Foto/Ist)," untuk foto berikut:



Sumber: https://jatim.sindonews.com

Medan wacana pada berita kedua yang diteliti, yakni pada Edisi Minggu 22 September 2019 menjelaskan hasil rekomendasi seminar internasional tentang peranan ahli hadis klasik-kontemporer dalam menanggulangi radikalisme. Secara online, berita di-upload pada pukul $12.50 \mathrm{WIB}$ itu didukung tampilan foto para narasumber sebagai realitas/ peristiwa/ kejadian seminar memuat lead bahwa Sekolah Tinggi Dirasat Islamiyah (STDI) Imam Syafi'i Jember, Jawa Timur, pada 20-21 September telah menggelar seminar bertema "Peranan Ahli Hadis Klasik dan Kontemporer dalam Menanggulangi Radikalisme".

Dalam berita kedua ini, peristiwa utama yang ditampilkan adalah berupa hasil seminar berupa 10 rekomendasi yang dimuat oleh Sindonews.com dengan 14 paper dalam 4 forum selama tiga hari pelaksanaan seminar internasional. Selain itu, diberitakan pakar/ ulama ahli hadis sebagai narasumber yang hadir dari tiga negara. Secara ringkas, konstruksi berita online Sindonews.com memuat 10 rekomendasi sebagai berikut.

Pertama, radikalisme adalah bentuk dari sikap ekstrim dan berlebih-lebihan dalam urusan agama, dan penyimpangan ekstrim dalam menyikapi berbagai realita kehidupan ${ }^{24}$. Kedua, berpegang teguh dengan ajaran agama dan meniti metode

\footnotetext{
${ }^{24}$ Makna radikalisme ini memiliki kemiripan dengan yang didefenisikan Irwan Masduqi bahwa radikalisme diartikan sebagai sikap fanatik kepada satu pendapat serta menegasikan pendapat orang lain, mengabaikan terhadap kesejarahan Islam, tidak dialogis, suka mengkafirkan kelompok lain yang tak sepaham, dan tekstual dalam memahami teks agama tanpa mempertimbangkan tujuan esensial syariat (maqashid al-syari"at). Periksa Saprialman, Peran
} 
yang lurus nan moderat, dan menjalankan syari'at Allah secara komprehensiv, lahir maupun batin tidaklah dapat dikatagorikan sebagai bentuk radikalisme.

Ketiga, berbagai aksi radikalisme yang terjadi di bebagai negara, tidak ada kaitannya dengan ajaran Islam. Hanya saja peliputan secara besar besaran oleh mass media kepada sebagian tindakan yang dilakukan oleh beberapa oknum umat islam menyebabkan sebagian kalangan dengan gegabah menuduh umat Islam sebagai aktor di balik semua tindakan radikal.

Keempat, diantara karakter utama agama Islam yang sempurna ialah sikap moderat dalam segala urusan, dan menentang segala bentuk pemikiran dan tindakan radikal serta segala tindak melampaui batas, karena semua itu tidak sejalan dengan ajaran syari'at Islam yang selalu mengedepankan kemudahan dan kelapangan bagi semua ummat.

Kelima, para ulama' hadis klasik maupun kontemporer selalu berperan secara aktif dan besar dalam upaya-upaya menanggulangi segala bentuk radikalisme. Keenam, diantara latar belakang munculnya pemikiran dan tindakan radikal ialah adanya kebodohan terhadap ajaran Islam dan adanya oknum oknum amatiran yang lancang mengajarkan agama tanpa bimbingan dari para ulama' yang benar benar berkompeten. Sebagaimana mereka biasa mengedepankan dalil-dalil Al Qur'an dan As Sunnah yang multi tafsir. Karena itu peserta seminar merekomendasikan agar para ulama' ahli hadis melipat gandakan kontribusinya dalam mengajarkan ilmu agama kepada masyarakat luas, terutama para pemuda dan pelajar.

Ketujuh, seluruh peserta seminar merekomendasikan agar semua pihak mengedepankan etika dalam berkomunikasi yang sesuai dengan ajaran sunnah Nabi, dan menghindari segala bentuk hate speech (ujaran kebencian), terutama para penyeru agama Allah Ta'ala, dan berperan aktif dalam menanggulangi peredaran ujaran kebencian.

Kedelapan, diantara metode penanggulangan radikalisme yang paling efektif ialah dengan mengajarkan sunnah sunnah Nabi shallallahu 'alaihi wa sallam.Kesembilan, peserta seminar menyeru kepada semua akademisi dan para penuntut ilmu untuk meningkatkah kajian kajian mereka kitab-kitab hadis, dengan seluruh kandungannya, baik yang berkaitan dengan akidah, ibadah, akhlaq, adab, hukum, kisah isah, dan lainnya.

Kesepuluh, menyadari akan bahaya dan besarnya kerusakan yang diakibatkan oleh radikalisme, maka Sekolah Tinggi Dirasat Islamiyyah (STDI) Imam Syafii Jember, selalu mengedepankan sikap moderat sebagai prinsip dasarnya dalam segala urusan, dan dalam mendidik mahasiswa-mahasiswanya untuk dapat memahami dan mengamalkan akidah Ahlissunnah wa Al Jama'ah, jauh dari segala

Guru Pendidikan Agama Islam dalam Mencegah Paham Radikalisme bagi Siswa di MTs Irsyadul Anam Kiyudan Selomartani Kalasan Sleman Yogyakarta (Yogyakarta: Tesis Fakultas Agama Islam, UII, Yogyakarta, 2018), 41-42. 
Al-Hikmah. Vol, 17 No. 2 Oktober 2019

bentuk pemikian dan tindakan radikal.

\section{Pelibat Wacana Kontra Radikalisme}

Dalam konteks pelibat wacanapada berita Sindonews.com Edisi Rabu 18 September 2019, Sindonews.com memuat identitas nara sumber yang menyampaikan pandangan mereka dalam seminar internasional. Redaksi Sindonews.com hanya mengandalkan keterangan sumber utama ketua panitia seminar internasional, yakni Dr. Ali Musri Semjan, MA sebagai ketua panitia untuk menjelaskan realitas seminar tersebut.

Pada berita pra seminar internasional, Sindonews.com menyebutkan keynote speaker dalam acara tersebut adalah Prof. Dr. Phil Kamaruddin Amin, MA selaku Dirjen Direktorat Jenderal Pendidikan Islam Kementerian Agama RI, Staf Khusus Presiden RI bidang Keagamaan Internasional, Dr Hj Siti Ruhaini Dzuhayatin MA serta Kepala BNPT Komjen Pol Drs Suhardi Alius.

Sindownews.com juga menyebutkan pembicara utama dalam seminar internasional ini adalah Syaikh Prof. Dr. Abdullah bin Abdul Aziz Al Faleh (Dekan Fak. Hadis dan Ilmu Hadis Univ Islam Madinah), Syaikh Prof. Dr. Ali Ibrahim Saud (Guru Besar Ilmu Hadis Univ Alu Al Bayt, Amman Yordania), Syaikh Prof. Dr. Abdus Sami' Muhammad Anis (Guru Besar Ilmu Hadis, Univ Sharjah, UEA) dan beberapa ulama-ulama hadis lainnya.Identitas lain yang dikonstruksikan oleh Sindonews.com adalah identitas penyelenggara acara, yakni Program Studi Ilmu Hadis STDI Imam Syafi'i Jember bekerja sama dengan ASILHA (Asosiasi Ilmu Hadis Indonesia) ${ }^{25}$.

Berita kedua yang diteliti, yakni Edisi Minggu 22 September 2019, Sindonews.com mengonstruksikan sumber-sumber yang sama dari berita yang pertama. Padahal, tidak semua nara sumber tersebut hadir dalam seminar internasional. Diantaranya, Prof. Dr. Phil. Kamarudin Amin, MA selaku Dirjen Pendis Kemenag RI, Staf Khusus Presiden RI bidang Keagamaan Internasional, Dr Hj Siti Ruhaini Dzuhayatin MA dan Kepala BNPT Komjen Pol Drs Suhardi Alius yang tidak hadir dalam acara tersebut, tetap saja ditulis oleh Sindonews.com.

Pihak panitia sendiri dalam tayangan langsung melalui siaran media sosial sudah menjelaskan ketidakhadiran ketiga narasumber ini. Penjelasan mengenai ketidakhadiran beberapa narasumber dijelaskan oleh Ketua ASILHA Dr Muhammad Al Fatih Suryadilaga. Selengkapnya seminar internasional ini dapat ditelusuri melalui media online YouTube https://www.youtube.com/watch?v =vAWtH2NHrf8, dengan judul "(FULL) Seminar Internasional: Peran Ulama Ahli

\footnotetext{
${ }^{25}$ Peserta yang hadir sebagaimana dilaporkan dalam web resmi STDI Imam Syafii Jember dalam laman http://stdiis.ac.id/berita/hadirkan-ahli-hadis-dari-6-negara-dalam-seminar-internasionalstdiis-jember-pangkas-definisi-liar-masyarakat-tentang-radikalisme/ disebutkan sebanyak 6 negara yang hadir sebagai pembicara.
} 
Hadis dalam Menanggulangi Radikalisme" yang saat diakses peneliti pada Sabtu 19 Oktober 2019 sudah disaksikan/ ditonton 6.074 kali dengan 268 like sejak diupload pada 21 September 2019.

Dalam konteks kelengkapan berita, Sindonews.com tidak melakukan peliputan secara langsung di lapangan. Hal ini dibuktikan dengan tidak ada satu pun narasumber yang diwawancarai pada berita yang kedua. Foto narasumber atau sumber informan yang ditampilkan juga bukan hasil karya jurnalistik dari wartawan/ jurnalis foto Sindonews.com sendiri, melainkan hasil kiriman dari tim panitia dengan menuliskan foto istimewa ${ }^{26}$ (foto/ist) sebagai simbol bukan karya redaksi media tersebut sebagaimana digambar berikut.

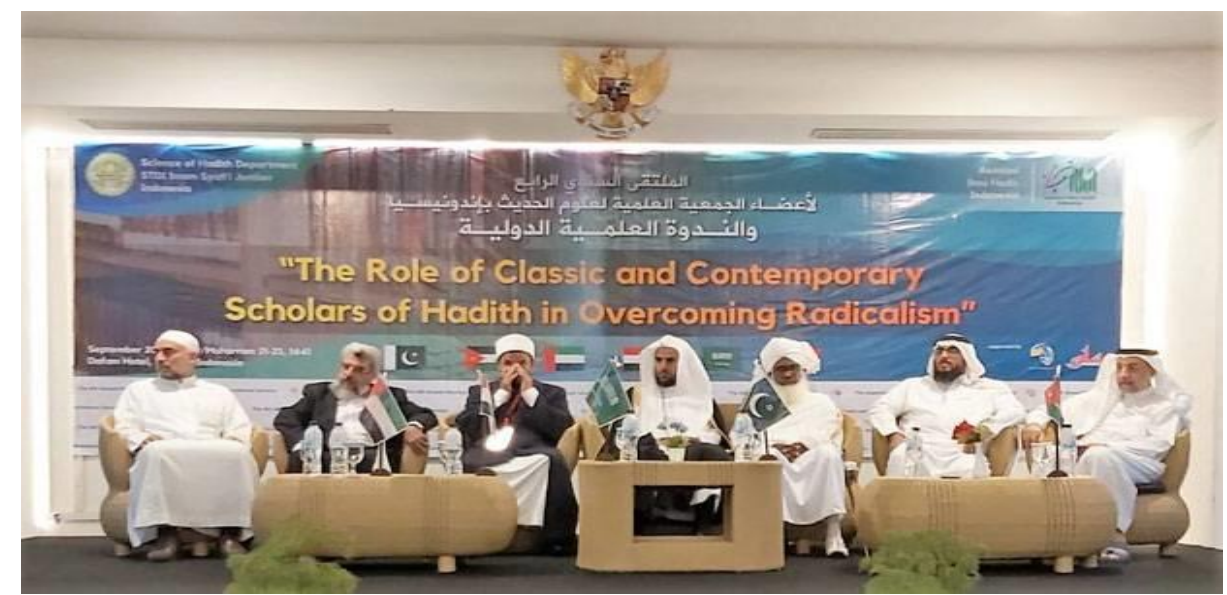

Sumber: https://jatim.sindonews.com/read/14802/1/

\section{Mode Wacana Anti Radikalisme}

Gaya bahasa yang dipilih oleh Sindonews.com pada berita pra seminar, yakni Rabu 18 September 2019 adalah naratif (cerita) berdasarkan satu sumber informasi ketua panitia seminar sebagaimana dijelaskan dalam dimensi kedua, yakni pelibat wacana. Hal ini menyebabkan subyektifitas peristiwa hanya diceritakan oleh satu orang untuk mewakili keseluruhan peristiwa yang berlangsung selama 3 hari. Dapat dinyatakan, pilihan bahasa redaksi dengan mengandalkan narasi satu orang sudah dipandang merepresentasikan konstruksi Sindonews.com terhadap peristiwa yang ditampilkan.

Gaya jurnalistik dikonstruksikan dalam judul yang mewakili isi berita dengan kalimat yang lugas, yakni "STDI Imam Syafii Jember Buat Seminar Internasional Kupas Peran Ulama Ahli Hadis Tanggulangi Radikalisme”. Konstruksi judul media online lebih bersifat memancing khalayak agar mengetahui peristiwa tersebut

\footnotetext{
${ }^{26}$ Dalam reportase langsung di lapangan, wartawan melengkapi dengan foto jurnalistik. Tetapi, Sindonews.com menggunakan foto dokumentasi lain, sehingga ditulis (foto/ist). Biasanya, jika foto hasil karya jurnalis akan ditulis sesuai dengan nama jurnalisnya.
} 
dengan mengakses atau meng-klik berita tersebut. Demikian pula pada berita kedua yang diunggah pada 22 September 2019, Sindonews.com menggunakan judul dengan gaya jurnalistik yang persuasif, yakni "Ini Rekomendasi Seminar Internasional Peranan Ahli Hadis Klasik-Kontemporer Menanggulangi Radikalisme" yang menunjukkan ajakan agar audience (khalayak dunia maya) mengakses hasil seminar yang berlangsung tiga hari tersebut. Sindonews.com menampilkan kalimat persuasif untuk menggambarkan hasil seminar dengan menggunakan kata dengan diksi yang menegaskan "Ini Rekomendasi....." yang memantik penasaran khalayak online untuk meng-klik berita tersebut.

Narasi yang dipilih oleh Sindonews.com dalam berita yang kedua, yakni Edisi Minggu 22 September 2019 juga berdasarkan hasil akhir ringkasan seminar dengan bahasa yang persuasif. Dengan menampilkan hasil seminar berupa 10 rekomendasi, Sindonews.com mengajak pembaca untuk memahami upaya penanggulangan radikalisme yang dilakukan kalangan ahli hadis, baik klasik dan kontemporer dari berbagai negara.

Bentuk persuasif itu dapat disimak dari penutup berita, Sindonews.com memilih diksi yang mendukung upaya kampus STDI dalam melawan radikalisme ${ }^{27}$. Konstruksi berita sebagai penutup dalam konsep penulisan jurnalistik model piramida terbalik dianggap tidak terlalu penting, tetapi sebagai bagian dari produk wacana yang ditawarkan kepada khalayak. Penyebutan nama STDI Imam Syafii sebagai penyelenggara juga dianggap mewakili pandangan kampus tersebut dalam melawan radikalisme sebagaimana tergambar dalam kalimat sebagai berikut:

"sebagaimana STDI Imam Syafii juga menanamkan metode pemikiran yang benar pada diri mahasiswanya, sehingga mereka memiliki daya imunitas terhadap berbagai bentuk pemikiran dan tindakan radikal."

Dalam hal ini, Sindonews.com ikut menegaskan posisinya dalam menarasikan STDI dalam melakukan peran akademis dalam penanggulangan pemikiran radikal. Statemen yang dipilih memiliki kemiripan dengan pernyataan Ketua STDI Imam Syafii Jember Dr. Arifin Badri yang dipublikasikan media online merdeka.com ${ }^{28}$ bahwa sejak mendapatkan izin berdiri dari pemerintah

\footnotetext{
${ }^{27}$ Sebelumnya perlawanan radikalisme ini didengungkan oleh Perguruan Tinggi Keagamaan Islam Negeri (PTKIN) dalam Deklarasi Aceh 26 April 2017 oleh 50 pimpinan (PTKIN) yang salah satu isinya melarang berbagai bentuk kegiatan yang bertentangan dengan Pancasila, dan anti-NKRI, intoleran, radikal dalam keberagamaan, serta terorisme. Pada 26 September 2017, seluruh pimpinan perguruan tinggi se-Indonesia mendeklarasikan anti radikalisme dan terorisme di Nusa Dua, Bali. Pada puncak peringatan Sumpah Pemuda ke-89, 28 Oktober 2017 pemerintah kembali merespons isu tersebut dengan menggelar Kuliah Akbar Aksi Kebangsaan Perguruan Tinggi Melawan Radikalisme yang berlangsung serentak di seluruh kota-kota di Indonesia. Periksa Kun Wazis, Hegemoni Dunia Islam melalui Globalisasi Isu Terorisme dan Radikalisme (Jember: Jurnal Al ‘Adalah, Vol. 20, No. 1, Mei 2017), 168

28 Periksa laman media online pada alamat https://www.merdeka.com/peristiwa/menolak-
} 
(Kementerian Agama Republik Indonesia), kampus STDI selalu berkomitmen dalam penanggulangan masalah sosial, diantaranya bahaya radikalisme yang dikemas dengan wajah agama.

\section{Kesimpulan}

Berdasarkan analisis wacana model Halliday dapat dinyatakan bahwa Sindonews.com dan sebagian media online lain mengonstruksi realitas seminar internasional yang digelar STDI Imam Syafii Jember mendasarkan pada sumber utama ketua panitia yang menyampaikan press release kepada media yang dituju. Hasil kajian wacana kritis pada artikel ini diantaranya:

1. Isu radikalisme menjadi perebutan berbagai kelompok kepentingan melalui beragam penafsiran. Media massa ikut mewacanakan pertarungan komunitas muslim terhadap realitas radikalisme melalui konstruksi berita di media massa, terutama media online.

2. Media massa, baik media cetak, media elektronik, dan media online mewacanakan SDTI Imam Syafii dan ASILHA sebagai salah satu kelompok yang layak ditampilkan gerakannya dalam menanggulangi bahaya radikalisme dalam konstruksi media.

3. Media online Sindonews.com mewacanakan perlawanan STDI Imam Syafii dan ASILHA dalam menanggulangi bahaya radikalisme melalui berita yang dikonstruksi Sindonews.com dengan dominasi satu sumber informan pihak STDI Imam Syafii untuk mewakili keseluruhan realitas peristiwa seminar internasional.

4. Media online Sindonews.com mewacanakan STDI Imam Syafii Jember dan ASILHA memiliki peran penting dalam ikut serta penanggulangan radikalisme berkedok agama yang dapat merusak ajaran Islam dan citra kaum muslimin.

\section{Daftar Pustaka}

BNPT. 2016. Strategi Menghadapi Paham Radikalisme Terorisme-ISIS. Dalam media siber dengan alamat https://belmawa.ristekdikti.go.id/wp-content/ uploads/2016/12/Strategi-Menghadapi-Paham-Radikalisme-Terorisme.pdf, diakses 22 Oktober 2019.

Buchori, Mochtar. 1986. Radikalisme Agama: Sebuah Catatan Awal. Jakarta: Majalah Pesantren No. 4/ Vol. III/ 1986, Perhimpunan Pengembangan Pesantren dan Masyarakat (P3M).

stigma-jenggot-dan-celana-cingkrang-identik-dengan-radikalisme.html 
Ghifari, Iman Fauzi. 2017. Radikalisme di Internet. Bandung: Religious, Jurnal Agama dan Lintas Budaya UIN Sunan Gunung Djati, Vol. 1, No.2, Maret 2017.

Haryatmoko, 2016. Critical Discourse Analysis (Analisis Wacana Kritis):

Landasan Teori, Metodologi dan Penerapan. Jakarta: Rajawali Pers

http://m.beritajatim.com/politik_pemerintahan/336542/kontroversi_wahabi_di_jem

ber_berakhir_damai.html

http://stdiis.ac.id/berita/hadirkan-ahli-hadis-dari-6-negara-dalam-seminar-

internasional-stdiis-jember-pangkas-definisi-liar-masyarakat-tentang-

radikalisme/

http://stdiis.ac.id/profil/sejarah-singkat/, diakses 22 Oktober 2019.

http://www.moslemtoday.com/ketegangan-antara-warga-nahdliyyin-dan-stdi-

imam-syafii-jember-akhirnya-mencair/

https://faktualnews.co/2018/08/03/anggap-stdi-diskriditkan-kiai-ratusan-massa-topi-

bangsa-wadul-ke-dewan/92122/

https://jatim.sindonews.com/read/14618/1/stdi-imam-syafii-jember-buat-seminar-

internasional-kupas-peran-ulama-ahli-hadits-tanggulangi-radikalisme-

1568786983

https://jatim.sindonews.com/read/14802/1/ini-rekomendasi-seminar-internasional-

peranan-ahli-hadits-klasikkontemporer-menanggulangi-radikalisme-

1569290997

https://kbbi.web.id/radikal, diakses 22 Oktober 2019.

https://kbbi.web.id/radikalisme, diakses 22 Oktober 2019.

https://khazanah.republika.co.id/berita/py212e313/ulama-hadis-dunia-gelar-

seminar-di-jember-bahas-radikalisme

https://mediaindonesia.com/read/detail/260994-stdi-imam-syafii-gelar-seminar-

internasional-cegah-radikalisme

https://www.asilha.com/tentang/, diakses 22 Oktober 2019.

https://www.merdeka.com/peristiwa/menolak-stigma-jenggot-dan-celana-

cingkrang-identik-dengan-radikalisme.html

https://www.merdeka.com/peristiwa/menolak-stigma-jenggot-dan-celana-

cingkrang-identik-dengan-radikalisme.html

https://www.youtube.com/watch?v=vAWtH2NHrf8, dengan judul “(FULL)

Seminar Internasional: Peran Ulama Ahli Hadis dalam Menanggulangi Radikalisme"

Kriyantono, Rachmat. 2012. Teknik Praktis Riset Komunikasi. Jakarta: Kencana Prenada Media Group. 
Perlawanan Ahli Hadis Terhadap Gerakan Radikalisme dalam Konstruksi Media Online

Mulyana, Deddy. 2008. Komunikasi Massa: Kontroversi, Teori dan Aplikasi. Bandung: Widya Padjadjaran.

Saprialman, 2018. Peran Guru Pendidikan Agama Islam dalam Mencegah Paham Radikalisme bagi Siswa di MTs Irsyadul Anam Kiyudan Selomartani Kalasan Sleman Yogyakarta. Yogyakarta: Tesis Fakultas Agama Islam, Universitas Islam Indonesia (UII) Yogyakarta.

Syuderajat, Fajar. 2017. Ideologi Surat Kabar dalam Pemberitaan Terorisme. Bandung: Jurnal Dakwah dan Komunikasi UIN Sunan Gunung Djati Vo. 1, No. $1,2017$.

Wazis, Kun. 2017. Hegemoni Dunia Islam melalui Globalisasi Isu Terorisme dan Radikalisme. Jember: Jurnal Al 'Adalah, Vol. 20, No. 1, Mei 2017, LP2M IAIN Jember. 